\title{
SCANNING ELECTROCHEMICAL MICROSCOPY: THEORY AND CHARACTERIZATION OF ELECTRODES OF FINITE CONICAL GEOMETRY
}

\author{
Cynthia G. Zoski ${ }^{*}$, Biao Liu², and Allen J. Bard ${ }^{2}$ \\ ${ }^{1}$ Department of Chemistry, Georgia State University, Atlanta, GA 30303 \\ Email: checgz@panther.gsu.edu \\ ${ }^{2}$ Department of Chemistry and Biochemistry, University of Texas at Austin, Austin, Texas \\ 78712 \\ Email: ajbard@mail.utexas.edu
}

Simulation programs (PDEase 2D, Macsyma Inc., Arlington, MA) for SECM over an insulator and conductor with a conical UME 


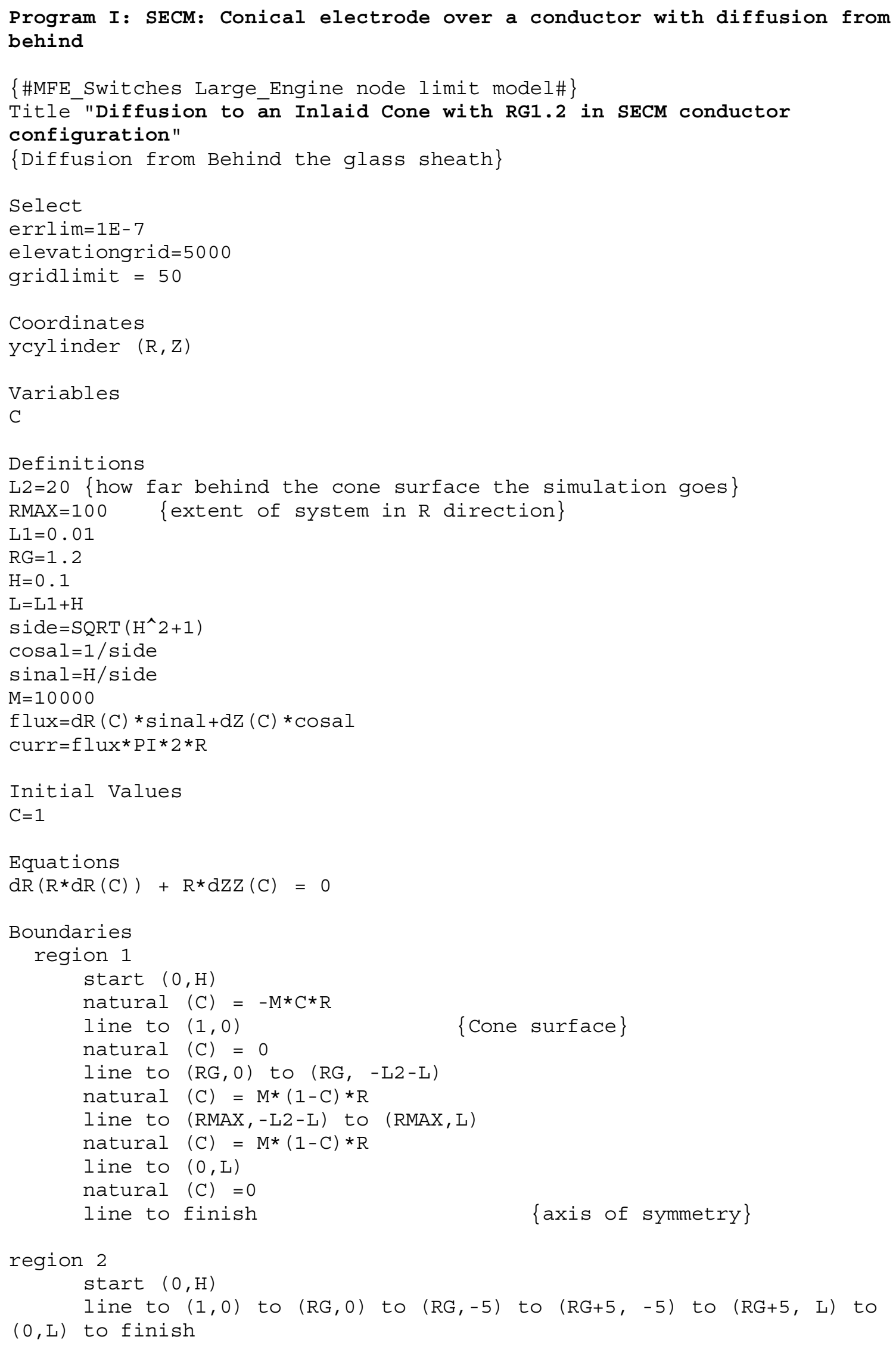




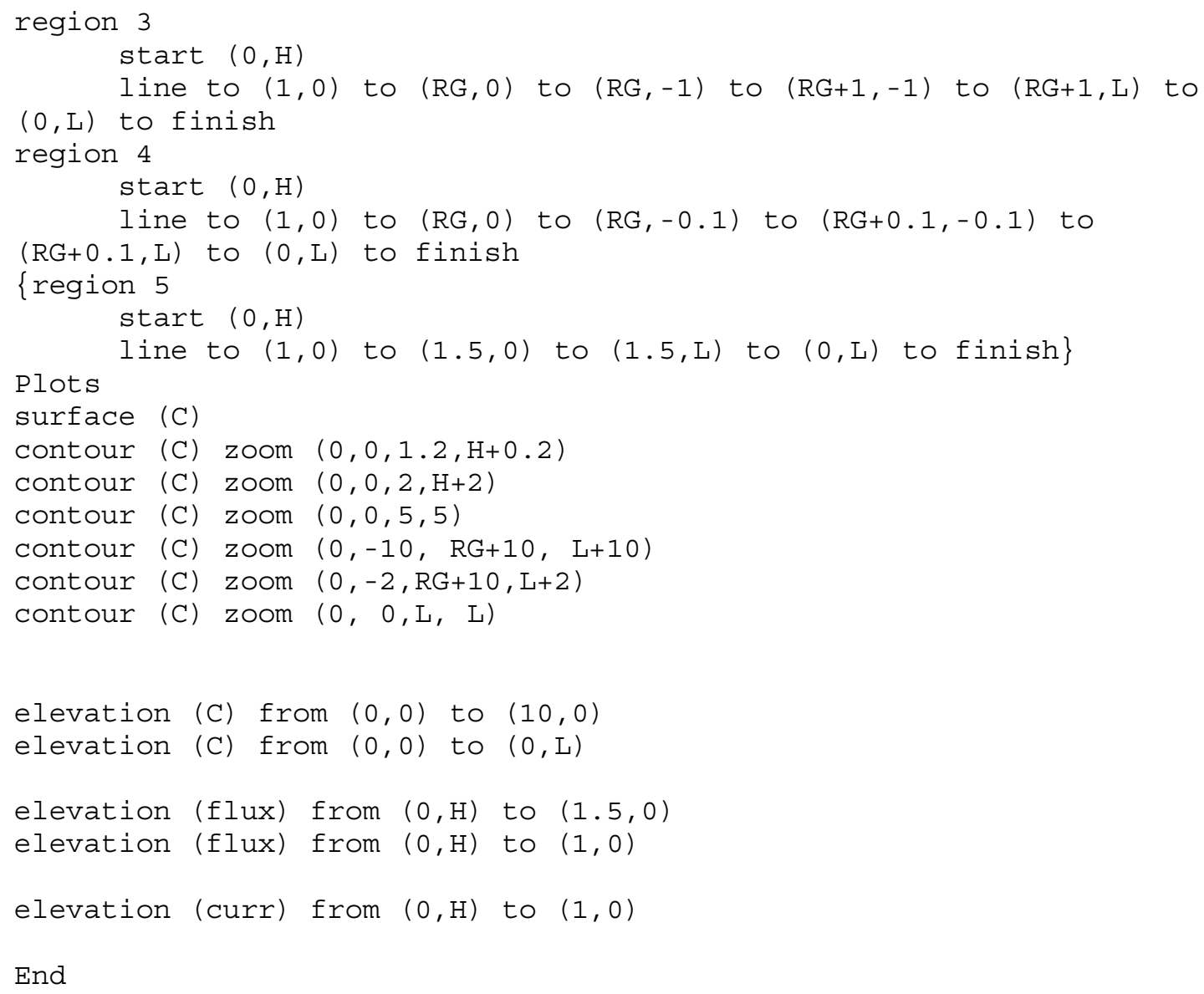




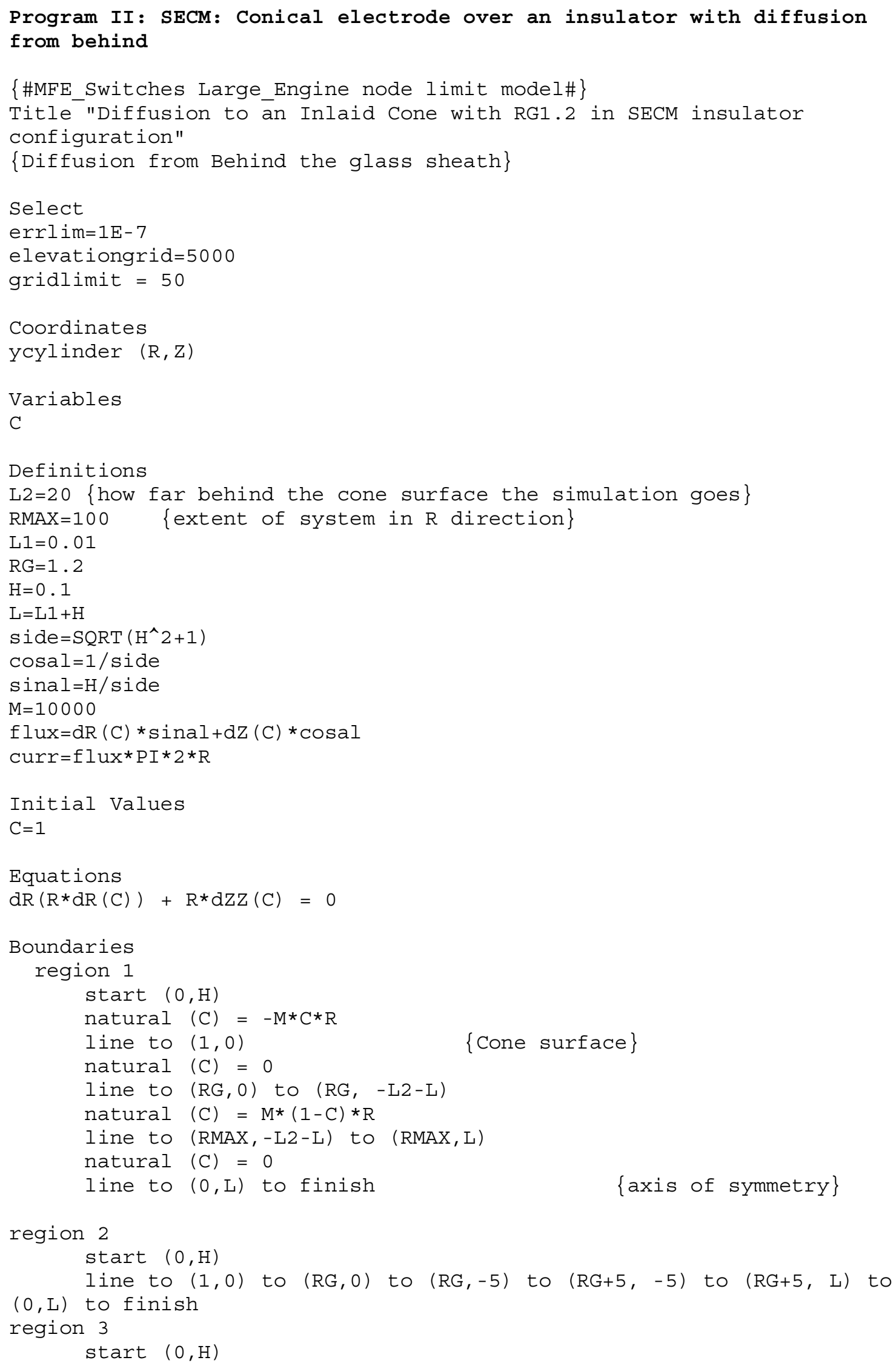




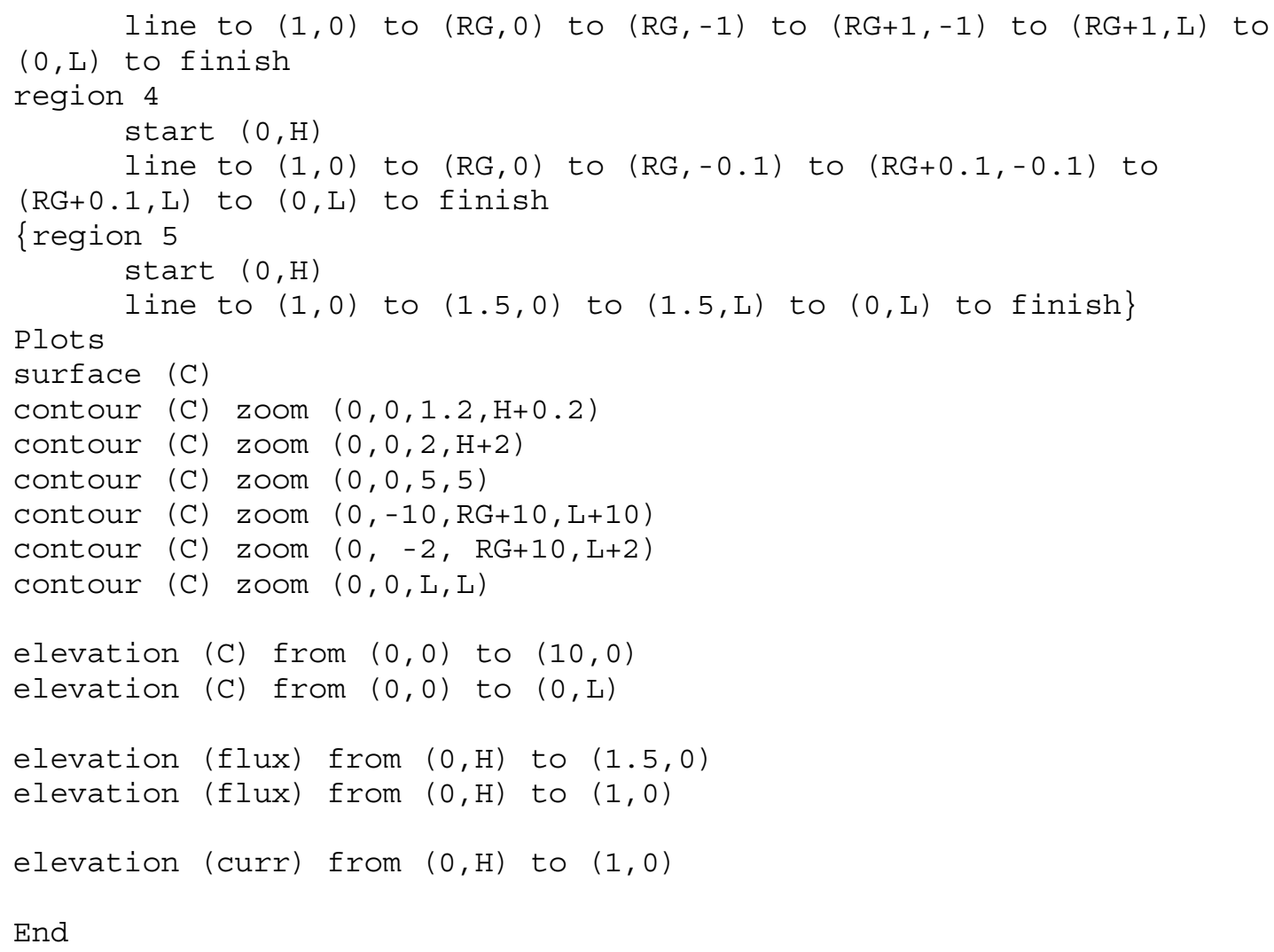

